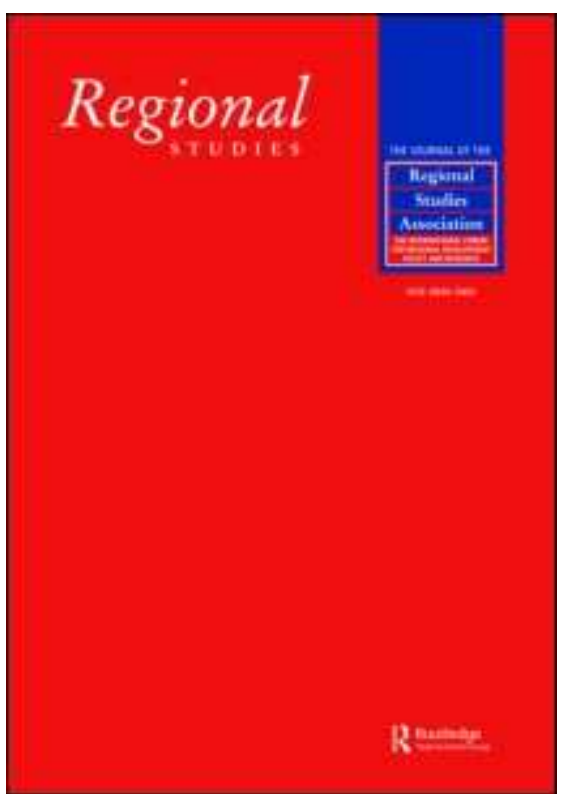

\title{
Unemployment volatility and regional specialization in the European Union
}

\begin{tabular}{|r|l|}
\hline Journal: & Regional Studies \\
\hline Manuscript ID: & CRES-2008-0153.R2 \\
\hline Manuscript Type: & Main Section \\
\hline JEL codes: & $\begin{array}{l}\text { R11 - Regional Economic Activity: Growth, Development, and } \\
\text { Changes < R1 - General Regional Economics < R - Urban, Rural, } \\
\text { and Regional Economics, R12 - Size and Spatial Distributions of } \\
\text { Regional Economic Activity < R1 - General Regional Economics < R } \\
\text { - Urban, Rural, and Regional Economics }\end{array}$ \\
\hline Keywords: & \begin{tabular}{l} 
unemployment, volatility, specialization, regions, European Union \\
\hline
\end{tabular} \\
\hline
\end{tabular}

\section{scholarONE" \\ Manuscript Central}




\title{
Roberto Ezcurra ${ }^{a}$
}

\author{
${ }^{a}$ Department of Economics \\ Universidad Pública de Navarra \\ Campus de Arrosadia $\mathrm{s} / \mathrm{n}$ \\ 31006 Pamplona (Spain) \\ Tel. $(+34) 948169359$ \\ Fax (+34) 948169721 \\ E-mail: roberto.ezcurra@unavarra.es
}

(Received July 2008; in revised form December 2009) 


\begin{abstract}
This paper examines the link between unemployment volatility and the sectoral composition of economic activity in the regions of the European Union over the period 1980-2004. To that end, I use different spatial econometric techniques, which allow one to investigate the role played in this context by spatial effects and geographical spillovers. The results show that unemployment volatility is positively related to regional specialization in the European Union. This finding does not depend on the use in the analysis of absolute or relative specialization measures.
\end{abstract}

\title{
VOLATILIDAD DE LAS TASAS DE DESEMPLEO Y ESPECIALIZACIÓN REGIONAL EN LA UNIÓN EUROPEA
}

\begin{abstract}
Este trabajo estudia la relación entre la volatilidad de las tasas de desempleo y la composición sectorial de la actividad económica en las regiones de la Unión Europea a lo largo del período 1980-2004. Para ello el autor utiliza diferentes técnicas de econometría espacial que permiten determinar la importancia en este contexto de la localización geográfica de las distintas regiones. El análisis llevado a cabo muestra que la volatilidad de las tasas de desempleo está correlacionada positivamente con el nivel de especialización regional. De hecho, este resultado no depende de la utilización en el análisis de medidas de especialización absolutas o relativas.
\end{abstract}

Palabras clave: Desempleo, volatilidad, especialización, regiones, Unión Europea. 
Código JEL: E32, R11, R12.

Keywords: unemployment, volatility, specialization, regions, European Union.

JEL classifications: E32, R11, R12. 


\section{Introduction}

Economic instability is generally viewed as an undesirable characteristic of a regional economy (Siegel et al., 1995; Wagner, 2000). This explains why the analysis of the causes of regional economic instability has been a recurring topic of interest in the literature during the last decades. Specifically, numerous studies have examined the role played in this context by the sectoral composition of economic activity (e.g. Conroy, 1975; Kort, 1981; Brewer and Moomaw, 1985; Attaran, 1986; Malizia and Ke, 1993; Baldwin and Brown, 2004; Trendle, 2006). In this regard, the traditional argument suggests the existence of a positive relationship between volatility and regional specialization. Thus, as a region's economy becomes more diversified, it is less affected by fluctuations caused by factors outside the region (Richardson, 1969). Likewise, regions with low levels of specialization are characterized by the presence of various industries that experience fluctuations of different intensity and timing. Consequently, employment losses in some sectors are offset by employment gains in other sectors, thus stabilizing the regional economy (Malizia and Ke, 1993). In view of these explanations, policy-makers often attempt to attract industries that will diversify their region's productive structure in order to promote economic stability and growth (Schoening and Sweeney, 1992; Izraeli and Murphy, 2003).

During the last decades several studies have examined empirically the link between regional volatility and the sectoral composition of economic activity using mainly US data (see Dissart (2003) for a review of this literature). Various authors have found that more industrial diversification leads to less instability (e.g. Kort, 1981; Malizia and Ke, 1993; Baldwin and Brown, 2004; Trendle, 2006), while the results obtained by other researchers suggest that the relationship is not statistically significant (Jackson, 1984; 
Attaran, 1986). Nevertheless, when assessing these findings, it should be noted that, as pointed out by Wagner and Deller (1998), most of these studies use small sample sizes, highly aggregated data sets, problematic measures of specialization and excessively simplistic statistical methods.

Against this background, and in a quest for empirically well-founded, stylized facts, this paper aims to investigate the relationship between unemployment volatility and the sectoral composition of economic activity, using data on 196 European Union (EU) regions over the period 1980-2004. At this point it needs to be said that, as far as I am aware, this is the first time that this issue is examined from a sample of EU regions. Although Longhi et al. (2005) have analysed the effects of industrial diversity on the cross-sectional variation of regional unemployment in the EU, no study has tackled so far the role played by regional specialization when attempting to explain unemployment fluctuations in this context. Nevertheless, there are several reasons to justify the need to analyse this topic in the European case. To start with, it is worth investigating to what extent the results obtained for other geographical settings hold for the EU regions. Furthermore, the study of the explanatory factors of the unemployment variability registered by the European regions is particularly relevant from a policy point of view. In that respect, it should be noted that the existence of high levels of unemployment volatility is a major threat to the achievement of economic and social cohesion within the EU, which is especially important in the context of the integration process currently underway (European Commission, 2004, 2007).

From a methodological perspective, this paper is characterized by the employment of various spatial econometric techniques (Haining, 1990; Anselin and Bera, 1998; 
Anselin, 2001). To the best of my knowledge, only Trendle (2006) has applied a similar approach to explore the link between industrial diversification and economic instability in the case of the local government areas of the Australian state of Queensland. This methodology allows one to investigate the role played in this context by spatial effects and geographical spillovers, paying particular attention to the spatial characteristics of the data. In relation to this, it needs to be recalled that different authors have found that the outcomes of the labour market in a specific region are affected by the situation of the labour markets in the neighbouring regions (e.g. Molho, 1995; López-Bazo et al., 2002; Overman and Puga, 2002).

The rest of the paper is structured as follows. In order to establish the conceptual framework in which to fit the study, section 2 presents an overview of the main theoretical arguments that can be used to justify the possible impact of productive specialization on regional instability. After describing briefly in section 3 the data used in the empirical analysis, section 4 examines existing disparities in unemployment variability across the EU regions by applying spatial exploratory techniques. In turn, section 5 uses various alternative specifications of a spatial econometric model to analyse the impact of regional specialization on the intensity of unemployment fluctuations. Finally, section 6 presents the main conclusions of the paper.

\section{Regional specialization and economic instability: Theoretical}

\section{framework}

The relationship among productive specialization, economic growth and instability has been widely examined in the literature using different approaches and methodological 
options. Within this framework, elementary economic theory emphasizes the important gains in terms of economic performance derived from specialization processes (Wagner and Deller, 1998; Izraeli and Murphy, 2003). In particular, the neoclassical trade model shows that regions (countries) should specialize in those activities in which they enjoy a comparative advantage over their trade partners. This has to do with the presence of spatial differences in relative factor endowments (Ohlin, 1933), or technological differences that apply across industries (Krugman, 1994). Likewise, the relevance of external economies may also lead to specialization at the industry level (Krugman, 1994). In view of these arguments, the important advances experienced by the economic integration processes during the last decades suggest that nowadays most regions may depend on a greater degree of specialization to maintain or increase their competitive edge (Baldwin and Brown, 2004) ${ }^{1}$.

Although the theoretical benefits derived from sectoral specialization are widely agreed on, various economists, geographers and regional scientists have pointed out repeatedly that specialization in a relatively small number of industries can increase the degree of economic instability (e.g. Conroy, 1975; Kort, 1981; Malizia and Ke, 1993; Wagner and Deller, 1998; Baldwin and Brown, 2004; Trendle, 2006). Specifically, these authors suggest that a high level of specialization may lead to a welfare loss for the economy as a whole that outweighs the potential gains derived from specialization. According to this argument, a brake should be placed on the development of the specialization processes.

The possible negative impact of productive specialization on economic instability follows from the simple observation of the risks faced by those regions with an 
excessive reliance on a small number of activities (Kort, 1981; Trendle, 2006). In particular, if a specific sector experiences a relatively important decline caused by demand-side or supply-side disturbances ${ }^{2}$, a region will be affected more severely if a large share of total employment is engaged in the sector in question. Accordingly, this suggests that regions highly dependent on a small group of industries will tend to be characterized by alternating periods of employment losses and out-migration, and periods with low unemployment and rapid in-migration (Gilchrist and St. Louis, 1991). On the contrary, the greater the dispersion of regional employment among the different sectors, the less likely a region is to be affected by severe cyclical fluctuations (Malizia and Ke, 1993; Dissart, 2003). Given that the various productive activities often experience fluctuations of different intensity and timing, a diversified sectoral structure implies in principle that employment losses in some industries can be offset by employment gains in other industries. Accordingly, low levels of productive specialization should contribute to reduce the intensity of unemployment variations, thus stabilizing the regional economy. Therefore, sectoral diversification can be interpreted in this context as a risk-spreading strategy to minimize the effects of external shocks on regional performance (Frenken et al., 2007).

Economic stability is generally considered as a positive characteristic of a regional economy since it promotes economic growth, stable incomes and low unemployment levels (Wagner, 2000). For this reason, reducing volatility has long been an important concern for regional policy-makers (e.g. Schoening and Sweeney, 1992). In that respect, the different arguments presented above suggest that a region wishing to decrease its degree of instability should see a diversified productive structure as a relevant goal of economic development. In order to achieve this aim, regional policy-makers often 
attempt to attract new industries that will diversify their region's economic base (Baldwin and Brown, 2004).

Nevertheless, as pointed out by Malizia and Ke (1993), in this context it is important to recall that the potential benefits derived from industrial diversity are conditioned in the final instance by differences in occupational staffing patterns among industries. The effectiveness of sectoral diversification in reducing unemployment requires that workers laid off in one industry should be able to find work in another regional industry. Likewise, it should not be overlooked that what really makes a region particularly vulnerable to economic shocks is its degree of specialization in cyclically sensitive activities (Garcia-Milá and McGuire, 1993).

\section{Data}

All the data used in this paper were drawn from the Cambridge Econometrics regional database, which is mainly based on information supplied by Eurostat. The sample consists of 196 NUTS-2 regions in the EU over the period 1980-2004 ${ }^{3}$. Nevertheless, the lack of complete series obliged to exclude from the study the countries incorporated into the EU in 2004 and 2007, the Länder of former East Germany, the Portuguese islands in the Atlantic, and the French Overseas Departments and Territories.

NUTS-2 data were chosen rather than other potential alternatives for various reasons. Thus, there are numerous works in which NUTS-2 regions have been used to investigate regional issues in the European context, which facilitates the comparison of the results with those of other studies. Furthermore, the employment of NUTS-2 regions 
is justifiable from the point of view of EU regional policy considerations. Indeed, since the 1989 reform of European regional policy, it is at this spatial level that eligibility under Objective 1 of the Structural Funds is determined. Finally, it should not be overlooked that this is the finest level at which there exists the statistical information needed to carry out this empirical study. Accordingly, the use of NUTS-2 data enables us to maximize the number of observations used in the econometric analysis performed in the paper.

\section{The spatial distribution of unemployment volatility across the}

\section{European regions}

Following the earlier studies by Attaran (1986) and Wagner and Deller (1998) for the US case, the present paper is focused on the analysis of the unemployment fluctuations experienced by the EU regions. Accordingly, the main study variable is the standard deviation of annual unemployment rates in each region over the period 1980-2004. As in Wagner and Deller (1998), I consider that larger fluctuations (i.e. higher standard deviation) in unemployment are associated with greater levels of economic instability. In that respect, it is well-known that important changes in the unemployment rate are often disruptive to a regional economy.

The empirical analysis begins by presenting in Figure (1) a first picture of the spatial distribution of the variable object of study across the sample regions. As can be observed, there are significant disparities in unemployment variability within the EU. Despite this fact, all the countries considered are characterized by the presence of regions with relatively low values of the study variable. Nevertheless, although there are 
some exceptions, the greatest fluctuations in the unemployment rate tend to be registered by regions situated in the periphery of the Union. In any event, leaving aside other considerations, it is important to note that this initial examination suggests that unemployment volatility is not randomly distributed across space in the EU. On the contrary, there seems to be a positive spatial relationship between adjacent areas, neighbouring regions registering similar values of the standard deviation of the unemployment rate over the sample period.

\section{[INSERT FIGURE 1 AROUND HERE]}

However, some caution is recommended when interpreting the information supplied by Figure (1), since the conclusions that might be drawn are highly sensitive to the number and width of the different intervals employed to represent the variable of interest. This suggests that additional analyses should be performed to determine with greater accuracy the degree of spatial interdependence between the values of the study variable at different geographical locations. Bearing this in mind, the preliminary evidence provided by Figure (1) was supplemented with a formal analysis of the possible presence of spatial autocorrelation in the sample under study ${ }^{4}$. To that end, I proceeded by calculating Moran's I and Geary's c global tests, defined respectively as (Cliff and Ord, 1972; Haining, 1990):

$$
I=\frac{n \sum_{i=1}^{n} \sum_{j=1}^{n} w_{i j}\left(y_{i}-\bar{y}\right)\left(y_{j}-\bar{y}\right)}{S_{0} \sum_{i=1}^{n}\left(y_{i}-\bar{y}\right)^{2}}
$$


and

$$
c=\frac{(n-1) \sum_{i=1}^{n} \sum_{j=1}^{n} w_{i j}\left(y_{i}-y_{j}\right)^{2}}{2 S_{0} \sum_{i=1}^{n}\left(y_{i}-\bar{y}\right)^{2}}
$$

where, in the present context, $y_{i}$ is the standard deviation of annual unemployment rates in region $i$ over the period 1980-2004, and $\bar{y}$ is the sample average. Likewise, $w_{i j}$ denotes the corresponding element of the spatial weight matrix $W$, with $\sum_{i=1}^{n} \sum_{j=1}^{n} w_{i j}=S_{0}$. In relation to their interpretation, it should be noted, that after standardization, a significant and positive (negative) value of Moran's I (Geary's c) will indicate the existence of positive spatial autocorrelation, while a significant and negative (positive) value of Moran's I (Geary's c) will indicate the presence of a pattern of spatial association between dissimilar values.

As can be checked in expressions (1) and (2), before performing these tests it is necessary to define a spatial weight matrix to capture the strength of the interdependence between each pair of regions $i$ and $j$. To do so, a first option is to use the concept of first order contiguity, according to which $w_{i j}=1$ if regions $i$ and $j$ are physically adjacent and 0 otherwise. However, the use of this type of matrix may raise problems in the European context, given that the presence of islands means that $W$ will include rows and columns containing only zeros. This implies that the observations in question are not considered in the analysis, which in turn has an effect on the interpretation of the results obtained. For this reason, the spatial weight matrix used in 
this paper takes into account interactions beyond adjacent regions. In particular, I considered a row-standardized matrix based on the inverse distance between the centroids of the various regions. This matrix relies on the idea that only geographical proximity matters in describing the interactions across regions, which is consistent with the recommendations of Anselin and Bera (1998). In any event, in order to check the robustness of the results, I considered different cutoff parameters above which spatial interactions are assumed negligible. Following the strategy adopted by Le Gallo and Dall'erba (2006), these cutoff parameters were defined according to the different quartiles of the distance distribution. Nevertheless, the findings were in all cases very similar to those described in the paper.

\section{[INSERT TABLE 1 AROUND HERE]}

Table 1 shows that the Moran's I (Geary's c) statistic calculated for the standard deviation of the unemployment rate in the sample regions is positive (negative) and statistically significant, which is clear evidence of the existence of a pattern of positive spatial association in this context, thus confirming the initial impression drawn from Figure (1). Accordingly, this shows that, in the European setting, spatially adjacent regions tend on the whole to exhibit similar levels of unemployment volatility. When interpreting this result, it is worth recalling that the empirical evidence provided by various studies reveals that the outcomes of the labour market in a specific region are related to the situation of the labour market in the neighbouring regions (e.g. Molho, 1995; López-Bazo et al., 2002; Overman and Puga, 2002). 
It is important to keep in mind, however, that Moran's I and Geary's c are calculated on a global basis for the whole of the sample. Hence, we do not know whether, irrespective of the overall dependence pattern, there are clusters of regions in which unemployment variability is higher or lower than in the neighbouring zones. This is particularly relevant when characterizing the spatial distribution of unemployment volatility across the EU regions. For this reason, and in order to complete the previous findings, I constructed the Moran scatterplot for the variable of interest (Figure 2). The Moran scatterplot is a graph on which the standardized values of the variable to be considered are plotted on the horizontal axis and the standardized spatial lag of the same variable on the vertical axis. Thus, the four quadrants correspond to different types of spatial association. As can be seen from Figure 2, 79\% of the regions considered are located in quadrants I and III. This confirms that the EU is characterized by the presence of spatial clusters of regions with similar levels of unemployment volatility, while there are relatively few cases in which a region registers a value of the variable under analysis markedly different from the average of its neighbours. Accordingly, the intensity of unemployment fluctuations in the EU follows specific spatial patterns, which highlights the importance of the geographical location of the sample regions in this context.

\section{[INSERT FIGURE 2 AROUND HERE]}

In Figure 3 the information provided by the Moran scatterplot is used to show the sign of spatial association in the different areas. Specifically, the clusters of regions with relatively low levels of unemployment volatility surrounded by regions with the same characteristic are situated in Denmark, the Netherlands, Belgium, Germany, Austria, the North of Italy and the United Kingdom. On the contrary, the map indicates that most of 
[INSERT FIGURE 3 AROUND HERE]

\section{Unemployment volatility and regional specialization}

The analyses performed in the preceding pages reveal the presence of significant disparities in the intensity of the unemployment fluctuations experienced by the EU regions. In order to investigate this issue more deeply, this section examines the possible influence in this context of regional specialization.

To do so, first it is necessary to measure the level of specialization of the sample regions. To that end, the literature uses a variety of indexes that enables the researcher to summarize the sectoral composition of the spatial unit object of analysis in a unique scalar (Combes and Overman, 2004; Duranton and Overman, 2005). Within this framework, I employed initially the Herfindahl index in order to quantify the degree of industrial diversification of the various regions considered in the study. This specialization index is defined as follows: 


$$
H_{i}=\sum_{s=1}^{S}\left(\frac{E_{i s}}{\sum_{s=1}^{S} E_{i s}}\right)^{2}
$$

where $E_{i s}$ is the level of employment of region $i$ in sector $s^{5}$. As can be checked, the value of the Herfindahl index ranges from $\frac{1}{S}$ when employment is evenly spread across the $S$ sectors, to 1 when all the employment is concentrated in the same sector. Therefore, the higher is the value of the index, the less sectorally diverse would a given region be.

The Herfindahl index is employed in this analysis rather than other indicators of sectoral diversity proposed in the literature because of its relation to the measure of risk in the portfolio theory (Baldwin and Brown, 2004). Nevertheless, it should be noted that the Herfindahl index is an absolute measure of specialization, since it does not take into account the productive structure of the remaining sample regions. In view of this, and in order to check the robustness of the results, I also employed a frequently used dissimilarity index popularized by Krugman (1991):

$$
K_{i}=\sum_{s=1}^{S}\left|\frac{E_{i s}}{\sum_{s=1}^{S} E_{i s}}-\frac{\sum_{j \neq i}^{n} E_{i s}}{\sum_{j \neq i}^{n} \sum_{s=1}^{S} E_{i s}}\right|
$$

This relative measure takes value 0 if region $i$ has a sectoral structure identical to that of the other regions. In turn, the upper bound for $K$ is 2 , which is obtained in the case of maximum dissimilarity between the region in question and the remaining sample 
regions. This index represents the distance between the vector of sector shares in region $i$ and the vector of sector shares in the regions other than $i$. Accordingly, it measures the extent to which region $i$ differs from the remaining sample regions in terms of sectoral composition $^{6}$.

To compute the Herfindahl index and the dissimilarity measure described above, the finest level of sectoral disaggregation with data availability in the EU at the NUTS-2 level during the study period was used. In particular, the sectoral classification employed is based on the following fifteen activities: Agriculture, Mining and energy, Food, beverages and tobacco, Textiles, Chemical products, Electrical and optical equipment, Transport equipment, Other manufacturing, Construction, Distribution services, Hotels and restaurants, Transport, storage and communications, Financial intermediation, Real estate, renting and business activities, and Non-market services. Accordingly, the data set covers the full range of economic activities, including agricultural and services. Using this information, both specialization indexes were calculated annually for each region, and averaged over the study period (see Table A1 in the Appendix for further details).

As mentioned in the introduction, the main aim of this paper is to investigate the link between unemployment volatility and regional specialization in the EU. To that end, let us consider the following model:

$$
\log y_{i}=\alpha+\beta \log S P E_{i}+X_{i} \delta+\sum_{c} \phi_{c} N_{i c}+\varepsilon_{i}
$$


According to the notation employed above, the independent variable is the standard deviation of annual unemployment rates in each region over the sample period. As for the independent variables, SPE denotes the specialization index, and $X$ is a set of additional regressors that control for other factors that are assumed to influence unemployment variability. In addition, by including national dummies, $N$, I also control for different institutional and structural factors, which may affect the independent variable (Longhi et al., 2005). Finally, $\varepsilon$ is the corresponding disturbance term.

Before discussing several technical issues in relation to the estimation of model (5), the series of variables that make up the vector $X$ are described. At this point, a word of warning is required. In particular, it should be noted that, while the choice of the selected variables is based on the literature on regional economic instability, it ultimately depends on the availability of reliable statistical data for the level of spatial disaggregation on which the study is focused.

Within this framework, I began by considering the possible relevance in this context of the size of the sample regions. In that respect, it needs to be recalled that various authors have pointed out that regional size is likely to be an important factor when explaining spatial differences in economic instability (e.g. Kort, 1981; Brewer and Moomaw, 1985; Begovic, 1992). For example, Malizia and Ke (1993) argue that regional instability will be greater in smaller economies than in larger ones. According to Trendle (2006), larger regions may have a greater ability to face the unfavourable effects of economic shocks than smaller regions as a result of the size of the regional labour market. More job seekers and more job offers mean more choice at both sides of the labour market, which leads in principle to better and quicker matches (Elhorst, 2001). Nevertheless, the 
opposite may also be true. In particular, larger regions are characterized by selling a relatively higher proportion of their production in the local market (Fujita et al., 1999). As mentioned by Baldwin and Brown (2004), this dependency of the local market implies that the growth rates in a region's industries will be correlated, since they are affected by the same economic shocks. Accordingly, if there are two regions with similar levels of productive specialization but different sizes, the larger region may register greater unemployment variability. In view of these arguments, the level of total employment was included in the model to capture the size of the sample regions.

In relation to this, it is important to recall that there are considerable differences in the geographical area of the various NUTS-2 regions (see Figure (1)). In this context it is likely that two regions with similar levels of total employment but different areas have labour markets with different characteristics, which may have influence on their ability to soak up the adverse effects of the economic cycle. In view of this, I consider that model (5) should take into account the degree of spatial concentration of employment within the various regions, in addition to the level of total employment. For this reason, I decided to incorporate in the list of regressors the employment density of the sample regions. Nevertheless, it needs to be said that it is difficult to determine beforehand the final effect of this variable on unemployment volatility. On the one hand, employment density may exert a positive influence on the efficiency of matching workers to jobs (Blackley, 1989; Partridge and Rickman, 1997). Consequently, this would imply that, ceteris paribus, employment losses in some activities will be offset more easily by employment gains in other activities in those regions with greater employment density. On the other hand, it should not be overlooked that a more dense labour market may increase the time needed to obtain information on job vacancies and job seekers and 
may present spatial frictions, which would have a negative effect on the probability of quick matches (Taylor and Bradley, 1997).

Malizia and $\mathrm{Ke}$ (1993) and Trendle (2006) have shown the relevance of the labour force characteristics in explaining economic instability. Bearing this in mind, I attempted to include in model (5) information on the quality of the labour force of the sample regions. However, this is not an easy task in the European regional context, since there are not data on the quality of the labour force at this level of territorial disaggregation throughout the study period. In view of this, I decided to use the ratio of active population to total population ${ }^{7}$. According to Fleisher and Rhodes (1976), low values in this variable in a specific region would be reflecting low levels of investment in human capital, which would result in higher risks for people with this characteristic to be laid off (Elhorst, 2003). This seems to suggest that regions with relatively higher ratios of active to total population will tend to register less fluctuations in their unemployment rates. At this point it needs to be mentioned that the relationship between unemployment and the ratio of active to total population is rather complex. In particular, as pointed out by Elhorst (2003), the ratio of active to total population may affect the unemployment rate and, in turn, be affected by this variable. This potential endogeneity problem should be borne in mind when considering the results derived from the estimation of model (5).

Furthermore, the role played in this context by regional growth patterns was examined. In relation to this, it is worth noting that Malizia and Ke (1993) have identified a Ushaped relationship between growth and regional economic instability. Accordingly, initially greater growth rates are associated with a lower degree of economic instability. 
Nevertheless, beyond a certain level, increases in the growth rates lead to higher instability. As pointed out by Baldwin and Brown (2004), there are different reasons that contribute to explain this non-linear relationship. To start with, those regions with very low or very high growth rates may be affected by specific economic shocks, which would tend to increase economic instability. In addition, regions with high growth rates are characterized in many cases by the presence of new industries that are inherently more volatile than mature industries. Additionally, it needs to be said that growth is often linked to the entry of new firms that register higher exit rates than older firms (Baldwin et al., 1999). Bearing this in mind, I included in the model the average annual growth rate of per capita GDP over the study period, as well as its square. Nevertheless, some caution is needed at this point. Specifically, it is worth mentioning that growth may be potentially endogenous in this context (Aghion and Banerjee, 2005), which should be taken into account when interpreting the results of the empirical analysis.

During the last decade most of the EU regions have experienced an important process of structural change, with an increasing relevance of the tertiary sector at the expense of the primary and secondary sectors (Gil et al., 2002). According to Trendle (2006), regions affected by structural change processes are generally characterized by jobs being either destroyed or created, or both simultaneously, which leads to the existence of discontinuities in regional labour markets. This suggests that structural change is likely to be an important determinant of unemployment volatility. In particular, it is expected that regions with higher levels of structural change tend to register higher unemployment volatility. In view of this, I calculated the amount of structural change experienced by each of the sample regions between 1980 and 2004 using the following formula (Trendle, 2006): 


$$
S C H_{i}=\sum_{s=1}^{S}\left|\frac{E_{i s, t_{1}}}{\sum_{s=1}^{S} E_{i s, t_{1}}}-\frac{E_{i s, t_{0}}}{\sum_{s=1}^{S} E_{i s, t_{0}}}\right|
$$

As can be observed, $\mathrm{SCH}$ quantifies the amount of structural change as the absolute value of the share of regional employment in sector $s$ in $t_{1}$ (2004) less the share of regional employment in that sector in $t_{0}$ (1980), summed over all sectors.

With the only exception of the structural change indicator, all the explanatory variables described above were obtained for each of the 25 years considered and averaged over time. Table A1 in the Appendix provides different descriptive statistics for these variables. In addition, Table A2 shows the correlation coefficients between the various explanatory variables used in the analysis.

Table 2 presents the main results obtained when the chosen model was estimated using the Herfindahl index to measure the level of regional specialization of the EU regions. In order to reduce any potential problem of endogeneity, different specifications were considered. As can be observed in the first three columns of the table, I began by estimating various versions of model (5) by ordinary least squares (OLS). Before discussing the results, however, it needs to be said that several tests were carried out to assess the adequacy of the approach employed. Specifically, the normality of the distribution of the error terms was examined. To that end, I calculated the Shapiro-Wilk test from the regression residuals. Nevertheless, the value of the statistic does not allow us to accept the null hypothesis of normality in all cases. This may be particularly 
relevant to justify the employment of various subsequent testing procedures. However, a detailed analysis of the distribution of the residuals shows that the non-normality is due exclusively to the existence of three extreme values corresponding to Kriti (Greece), Bolzano-Bozen (Italy) and Lancashire (United Kingdom). Once these observations have been removed from the sample, the distribution of the error terms is normal in all cases. Given that the results are very similar in both cases, I decided to keep all the observations in the analysis in order to maintain the whole sample of European regions.

Furthermore, the analyses performed in the previous section highlighted clearly the importance of spatial effects in explaining the regional distribution of unemployment variability in the EU. Bearing this in mind, I calculated various spatial dependence tests based on the residuals provided by the OLS estimations. In particular, I computed the Moran's I test (Cliff and Ord, 1972), the Lagrange multiplier tests for the spatial error model (LMERR) and the spatial lag model (LMLAG) proposed respectively by Burridge (1980) and Anselin (1988a), plus their robust versions (R-LMERR and RLMLAG) (Anselin et al., 1996). These tests were calculated initially using the spatial weight matrix defined in the previous section. As mentioned above, this spatial weight matrix is based on pure geographical distance. Accordingly, it is strictly exogenous to the model, thus avoiding the identification problems raised by Manski (1993). Table 2 shows that the results of the Moran's I test lead in all cases to the rejection of the null hypothesis of absence of residual spatial dependence, despite that model (5) includes national dummies. In order to decide the most appropriate specification in this context, I followed the classical approach in the spatial econometric literature and considered the degree of statistical significance of the various Lagrange multiplier tests (Anselin and Rey, 1991). Since LMLAG and R-LMLAG are respectively more significant than 
LMERR and R-LMERR in all cases, I selected the spatial lag model as the best specification ${ }^{8}$. Accordingly, the spatial lag of the dependent variable should be included in the list of regressors. That is,

$$
\log y_{i}=\alpha+\beta \log S P E_{i}+X_{i} \delta+\lambda W \log y_{i}+\sum_{c} \phi_{c} N_{i c}+\varepsilon_{i}
$$

where $\lambda$ is the spatial autoregressive parameter.

\section{[INSERT TABLE 2 AROUND HERE]}

The estimation of model (7) by OLS is inconsistent due to simultaneity induced by the spatial lag. Maximum likelihood (ML) estimators have been proposed to provide consistent estimates (Anselin, 1988b). In view of this, the last three columns in Table 2 show the ML estimates of various versions of the spatial lag model (7). Following the suggestion of White (1982) and Davidson and MacKinnon (1993), reported standard errors come from the heteroskedasticity consistent estimator of the covariance matrix of the maximum likelihood parameters.

As can be seen, the spatial autoregressive parameter is positive and statistically significant in all cases. In fact, the results of the Wald test and the Lagrange multiplier test for $\lambda=0$ confirm the statistical adequacy of the spatial lag model in this context. Accordingly, the empirical evidence provided by Table 2 indicates clearly that the degree of unemployment volatility in the neighbouring regions contributes to explain the variation of the dependent variable, which is in line with the findings in section 4. 
In any event, as stated earlier, the main aim of this paper is to investigate the link between unemployment volatility and sectoral specialization in the EU regions. In that respect, the estimation of the spatial lag model specified above yields interesting results. Thus, the information supplied by Table 2 reveals that the coefficient of the Herfindahl index is in all cases positive and statistically significant. This indicates the existence of a positive relationship between unemployment variability and sectoral diversification in the EU regions. This result is in fact robust to the inclusion in the analysis of additional explanatory variables. Hence, the estimates support the hypothesis that those regions characterized by greater levels of sectoral diversification tend to register lower unemployment volatility in the European context, which is consistent with the results obtained previously for the US states by Wagner and Deller (1998) using a different methodological approach based on a regional input-output model. Likewise, several authors have provided empirical evidence for various geographical settings showing that industrial diversity has a positive impact on economic stability (e.g. Kort, 1981; Malizia and Ke, 1993; Baldwin and Brown, 2004; Trendle, 2006). Nevertheless, some caution is required when comparing the results of the present paper with the findings obtained in these earlier studies, since in most cases there are differences in the dependent variable ${ }^{9}$.

With respect to the different control variables mentioned above, Table 2 indicates that all of them are statistically significant. In particular, the size of the regional labour market is negatively correlated with the dependent variable, suggesting that larger regions experience lower unemployment volatility. In turn, employment density has a positive influence on the dependent variable. The analysis carried out also reveals that regions with higher ratios of active population to total population register less 
fluctuations in their unemployment rates. Furthermore, Table 2 suggests the existence of a non-linear relationship between economic growth and the dependent variable. Specifically, the signs of the coefficients associated with the average annual growth rate and with its square show a U-shaped link between economic performance and regional instability. Finally, the indicator used to quantify the amount of structural change experienced by the sample regions is positively correlated with the dependent variable. This means that structural change processes contribute to increase unemployment volatility. Nevertheless, according to the above discussion, these findings should be treated with some caution, due to the possible mutual dependency between several of the regressors included in vector $X$ and the dependent variable. In any event, it is important to note that the coefficient of the Herfindahl index is positive and statistically significant in the different specifications of model (7) considered, regardless of the specific control variables included in each case. This suggests that the main result of the paper is not affected by potential endogeneity between some of the regressors and the dependent variable.

Having reached this point, it is worth noting that the observed link between unemployment volatility and industry mix may be sensitive to the specific measure of specialization used in the study. Bearing this in mind, previous analyses were repeated substituting the Herfindahl index with the dissimilarity index defined above. The results are shown in Table 3. As can be observed, the coefficient of the dissimilarity index is positive and statistically significant in all cases, which supports the previous conclusions. Hence, the detected relationship between unemployment volatility and the sectoral composition of economic activity within the EU still holds when a measure of relative specialization is employed in the analysis ${ }^{10}$. Additionally, with regard to the 
remaining explanatory variables, it is interesting to note that the results in Table 3 are very similar to those discussed above.

\section{[INSERT TABLE 3 AROUND HERE]}

The empirical evidence provided by Tables 2 and 3 confirms clearly that regional specialization has a positive impact on the intensity of unemployment fluctuations in the EU. Nevertheless, the analysis carried out thus far does not supply any information on the role played in this context by the various sectors, which prevents us from isolating the effects of different productive structures on unemployment volatility. In view of this, and in order to complete the previous results, I decided to use an alternative specification of model (5) in which the specialization index was replaced with the employment share in each of the fifteen sectors with data availability at the level of territorial disaggregation considered in the study.

Table 4 summarizes the main results of this analysis. It is worth noting that, following the specification search approach adopted above, and given the values of the different spatial dependence tests calculated from the OLS residuals, the estimation of the spatial lag model by ML is again the preferred specification in all cases. That said, we can observe that the employment share in Mining and energy is positively correlated with unemployment volatility. When interpreting this result, it needs to be recalled that this industry is highly variable and provides basic inputs to many other activities. As pointed out by Garcia-Milá and McGuire (1993), this implies that a relatively important presence of this sector increases the degree of exposure of the region to the shifts in the economic cycle. The Construction sector has a similar effect on unemployment 
variability, which is not particularly surprising if we take into account that this industry is highly cyclical. By contrast, those regions specialized in relatively low-tech and labour-intensive activities, such as Food, beverages and tobacco, Textiles, and Other manufacturing, experience less fluctuations in their unemployment rates. This suggests that these sectors may contribute to diversify the risks of a downturn in the regional economy. In turn, the estimates indicate that the employment share in Non-market services is positively correlated with the dependent variable. In that respect, it should be recalled that regions with a large non-market oriented sector are by definition less affected by changes in the overall economic conditions (e.g. Kangasharju and Pekkala, 2004). In this context, public employment and transfers play a relevant role (RodríguezPose and Fratesi, 2007). This means that the creation and destruction of employment in these regions tends to be more related to political than to economic decisions, which may have repercussions on their level of stability in the long term. Finally, it is worth mentioning that, as can be seen in Table 4, the coefficients of the employment shares in the remaining sectors are not statistically significant.

\section{[INSERT TABLE 4 AROUND HERE]}

\section{Conclusions}

This paper has investigated the link between unemployment volatility and the sectoral composition of economic activity in 196 EU regions during the period 1980-2004. To that end, I have applied spatial exploratory techniques and spatial econometric models, which has allowed me to take into account explicitly the role played by spatial effects in this context. 
The results show that there are relatively important differences in the intensity of the unemployment fluctuations experienced by the European regions. Although there are some exceptions, the highest levels of volatility tend to be registered by regions in the EU periphery. On the contrary, the regions with less variability in their unemployment rates are generally located in the central areas of the Union. This spatial pattern suggests that the study variable is not randomly distributed across the European space. Specifically, the analysis carried out reveals the existence of positive spatial autocorrelation in this context. Accordingly, neighbouring regions tend on the whole to experience similar levels of unemployment volatility.

The information provided by estimating a spatial lag model indicates that unemployment volatility is positively related to regional specialization. Hence, those EU regions with relatively low levels of sectoral specialization are characterized in general by registering less fluctuations in their unemployment rates. This result is in fact robust to the inclusion in the analysis of additional explanatory variables, such as the level of total employment, employment density, the ratio of active population to total population, the economic growth rate, and the amount of structural change experienced by the region in question. Likewise, the estimates show that the observed link between unemployment variability and the sectoral composition of economic activity does not depend on the employment in the analysis of absolute or relative specialization measures.

In order to complete these findings, I have also examined the role played in this context by the various sectors considered. This has allowed me to determine the influence of 
different sectoral structures on unemployment variability. In that respect, the results reveal that the intensity of unemployment fluctuations is positively correlated with the regional employment share in Mining and energy, Construction and Non-market services. By contrast, regions specialized in Food, beverages and tobacco, Textiles, and Other manufacturing, register relatively low levels of unemployment volatility. 


\section{Acknowledgments}

The author is grateful to the editors of Regional Studies and two anonymous referees for their insightful comments to earlier versions of the paper. This research has benefited from the financial support of the Spanish Ministry of Science and Innovation (Project ECO2008-05072-C02-02/ECON). 


\section{References}

AGHION P. and BANERJEE A. (2005) Volatility and Growth. Oxford University Press, New York.

ANSELIN L. (1988a) Lagrange multiplier test diagnostics for spatial dependence and spatial heterogeneity, Geographical Analysis 20, 1-17.

ANSELIN L. (1988b) Spatial Econometrics: Methods and Models. Kluwer Academic, Dordrecht.

ANSELIN L. (1995) Local indicators of spatial association-LISA, Geographical Analysis 27, 93-115.

ANSELIN L. (2001) Spatial econometrics, in BALTAGI B. (Ed), Companion to Theoretical Econometrics, pp. 310-330. Basil Blackwell, Oxford.

ANSELIN L. and BERA A. (1998) Spatial dependence in linear regression models with an introduction to spatial econometrics, in ULLAH A. and GILES D.E.A. (Eds) Handbook of Applied Economic Statistics, pp. 237-289. Springer-Verlag, Berlin.

ANSELIN L. and REY S.J. (1991) Properties of tests for spatial dependence in linear regression models, Geographical Analysis 23, 112-131.

ANSELIN L., BERA A., FLORAX R. and YOON M. (1996) Simple diagnostic tests for spatial dependence, Regional Science and Urban Economics 26, 77-104.

ATTARAN M. (1986) Industrial diversity and economic performance in US areas, Annals of Regional Science 20, 44-54.

BALDWIN J.R. and BROWN W.M. (2004) Regional manufacturing employment volatility in Canada: the effects of specialisation and trade, Papers in Regional Science 83, 519-541. 
BALDWIN J.R., BIAN L., DUPUY R. and GELLATLY G. (1999) Failure rates for new Canadian firms: new perspectives on entry and exit. Catalogue 61-526-XPE. Statistics Canada, Ottawa.

BEGOVIC B. (1992) Industrial diversification and city size: the case of Yugoslavia, Urban Studies 29, 77-88.

BLACKLEY P.R. (1989) The measurement and determination of state equilibrium unemployment rates, Southern Economic Journal 56, 440-456.

BREWER H.L. and MOOMAW R.L. (1985) A note on population size, industrial diversification and regional economic instability, Urban Studies 22, 349-354.

BRÜLHART M. and TRAEGER R. (2005) An account of geographic concentration patterns in Europe, Regional Science and Urban Economics 35, 597-624.

BURRIDGE P. (1980) On the Cliff-Ord test for spatial autocorrelation, Journal of the Royal Statistical Society B 42, 107-108.

CLIFF A. and ORD J. (1972) Testing for spatial autocorrelation among regression residuals, Geographical Analysis 4, 267-284.

COMBES P.P. and OVERMAN H.G. (2004) The spatial distribution of economic activities in the European Union, in HENDERSON V. and THISSE J.F. (Eds) Handbook of Urban and Regional Economics, Vol. 4, pp. 2845-2910. NorthHolland, Amsterdam.

CONROY M. (1975) The concept and measurement of regional industrial diversification, Southern Economic Journal 41, $492-505$.

DAVIDSON R. and MACKINNON J.G. (1993) Estimation and Inference in Econometrics. Oxford University Press, Oxford.

DISSART J.C. (2003) Regional economic diversity and regional economic stability: Research results and agenda, International Regional Science Review 26, 423-446. 
DURANTON G. and OVERMAN H.G. (2005) Testing for localisation using microgeographic data, Review of Economic Studies 72, 1077-1106.

ELHORST J.P. (2001) The mystery of regional unemployment differentials: a survey of theoretical and empirical explanations. Research Report 00C06, University of Groningen, Research Institute SOM (Systems, Organisations and Management).

ELHORST J.P. (2003) The mystery of regional unemployment differentials: a survey of theoretical and empirical explanations, Journal of Economic Surveys 17, 709-748.

EUROPEAN COMMISSION (2004) Third Report on Economic and Social Cohesion. Office for Official Publications of the European Communities, Luxembourg.

EUROPEAN COMMISSION (2007) Fourth Report on Economic and Social Cohesion. Office for Official Publications of the European Communities, Luxembourg.

FLEISHER B.M. and RHODES G. (1976) Unemployment and the labor force participation of married man and women: A simultaneous model, Review of Economics and Statistics 58, 398-406.

FRANKEL J.A. and ROSE A.K. (1998) The endogeneity of the optimum currency area criteria, Economic Journal 108, 1009-1025.

FRENKEN K., VAN OORT F. and VERBURG T. (2007) Related variety, unrelated variety and regional economic growth, Regional Studies 41, 685-697.

FUJITA M., KRUGMAN P. and VENABLES A.J. (1999) The Spatial Economy: Cities, Regions and International Trade. MIT Press, Cambridge (Massachusetts).

GARCIA-MILÁ T. and MCGUIRE T.J. (1993) Industrial mix as a factor in the growth and variability of states' economies, Regional Science and Urban Economics 23, 731-748. 
GIL C., PASCUAL P. and RAPÚN M. (2002) Structural change, infrastructure and convergence in the regions of the European Union, European Urban and Regional Studies 9, 115-135.

GILCHRIST D.A. and ST. LOUIS L.V. (1991) Directions for diversification with an application to Saskatchewan, Journal of Regional Science 31, 273-289.

HAINING R. (1990) Spatial Data Analysis in the Social and Environmental Sciences. Cambridge University Press, Cambridge.

IZRAELI, O. and MURPHY K.J. (2003) The effect of industrial diversity on state unemployment rate and per capita income, Annals of Regional Science 37, 1-14.

JACKSON R. (1984) An evaluation of alternative measures of regional industrial diversification, Regional Studies 18, 103-112.

KALEMLI-OZCAN S., SORENSEN B.E. and YOSHA O. (2001) Economic integration, industrial specialization, and the asymmetry of macroeconomic fluctuations, Journal of International Economics 55, 107-137.

KANGASHARJU A. and PEKKALA S. (2004) Increasing regional disparities in the 1990s: the Finnish experience, Regional Studies 38, 255-267.

KORT J. (1981) Regional economic instability and industrial diversification in the US, Land Economics 57, 596-608.

KRUGMAN P. (1991) Geography and Trade. Cambridge (Massachusetts), MIT Press.

KRUGMAN P. (1993) Lessons of Massachusetts for EMU, in GAVAZZI F. and TORRES F. (Eds) The Transition to Economic and Monetary Union in Europe, pp. 241-261. Cambridge University Press, New York.

KRUGMAN P. (1994) Rethinking International Trade. MIT Press, Cambridge (Massachusetts). 
LE GALLO J. and DALL'ERBA S. (2006) Evaluating the temporal and spatial heterogeneity of the European convergence process, 1980-1999, Journal of Regional Science 46, 269-288.

LONGHI S., NIJKAMP P. and TRAISTARU I. (2005) Is sectoral diversification a solution to unemployment? Evidence from EU regions, Kyklos 58, 591-610.

LÓPEZ-BAZO E., DEL BARRIO T. and ARTIS M. (2002) The regional distribution of Spanish unemployment: a spatial analysis, Papers in Regional Science 81, 365-389.

MALIZIA E.E. and KE S. (1993) The influence of economic diversity on employment and stability, Journal of Regional Science 33, 221-235.

MANSKI C.F. (1993) Identification of endogenous social effects: the reflection problem, Review of Economic Studies 60, 531-542.

MOLHO I. (1995) Spatial autocorrelation in British unemployment, Journal of Regional Science 35, 641-658.

OHLIN B. (1933) Interregional and International Trade. Harvard University Press, Cambridge (Massachusetts).

OVERMAN H.G. and PUGA D. (2002) Unemployment clusters across Europe's regions and countries, Economic Policy 34, 115-147.

PARTRIDGE M.D. and RICKMAN D.S. (1997) The dispersion of US state unemployment rates: The role of market and non-market equilibrium factors, Regional Studies 31, 593-606.

RICHARDSON H.W. (1969) Regional Economics. Praeger, New York.

RODRÍGUEZ-POSE A. and FRATESI U. (2007) Regional business cycles and the emergence of sheltered economies in the Southern periphery of Europe, Growth and Change 38, 621-648. 
SCHOENING N.C. and SWEENNEY L.E. (1992) Proactive industrial development strategies and portfolio analysis, Review of Regional Studies 22, 227-238.

SIEGEL P.B., ALWANG J. and JOHNSON T.G. (1995) A structural decomposition of regional economic instability: a conceptual framework, Journal of Regional Science $35,457-470$.

TAYLOR J. and BRADLEY S. (1997) Unemployment in Europe: A comparative analysis of regional disparities in Germany, Italy and the UK, Kyklos 50, 221-245.

TRENDLE B. (2006) Regional economic instability: the role of industrial diversification and spatial spillovers, Annals of Regional Science 40, 767-778.

WAGNER J.E. (2000) Regional economic diversity: Action, concept, or state of confusion, Journal of Regional Analysis and Policy 30, 1-22.

WAGNER J.E. and DELLER S.C. (1998) Measuring the effects of economic diversity on growth and stability, Land Economics 74, 541-556.

WHITE H. (1980) A heteroskedasticity-consistent covariance matrix estimator and a direct test for heteroskedasticity, Econometrica 48, 817-838.

WHITE H. (1982) Maximum likelihood estimation of misspecified models, Econometrica 50, 1-26. 


\section{Appendix}

[INSERT TABLE A1 AROUND HERE]

[INSERT TABLE A2 AROUND HERE]

[INSERT TABLE A3 AROUND HERE] 


\section{Notes}

${ }^{1}$ During the last fifteen years different studies have examined the links between economic integration, productive specialization and the degree of symmetry in the economic cycle. See, for example, Krugman (1993), Frankel and Rose (1998) or Kalemli-Ozcan et al. (2001).

${ }^{2}$ The analysis of the different sources of economic instability is beyond the scope of this paper. For further details, see Siegel et al. (1995).

${ }^{3}$ NUTS is the French acronym for "Nomenclature of Territorial Units for Statistics", a hierarchical classification of subnational spatial units established by Eurostat. In this classification, NUTS-0 corresponds to country level, while increasing numbers indicate increasing levels of subnational disaggregation.

${ }^{4}$ Spatial autocorrelation can be defined as the coincidence of value similarity with locational similarity (Anselin, 2001).

${ }^{5}$ I decided to use the level of employment as the reference variable instead of production to avoid problems of currency conversion inherent in value data (Brülhart and Traeger, 2005).

\footnotetext{
${ }^{6}$ As a sensitivity analysis, I also employed an alternative index similarly defined except using the square rather than the absolute value in expression (4). The results, however, were very similar in both cases.

${ }^{7}$ The participation rate was not employed due to the lack of data on the working-age population for the sample regions.
} 


\footnotetext{
${ }^{8}$ In order to check the validity of the decision rule used to choose this specification, I also estimated an alternative model including a spatial autoregressive structure in the error term (spatial error model). The results are presented in Table A3 in the Appendix. It is worth noting that the spatial lag model achieves a better fit than the spatial error model in all cases, thus confirming that the spatial lag model is the preferred specification in this context.
}

\footnotetext{
${ }^{9}$ Although there are some exceptions, most of these studies use a variance-based statistic applied to employment data. See Dissart (2003) for further details on this issue.

10 I also investigated the possible presence of a non-linear relationship between the specialization indexes and the dependent variable. To that end, I considered different alternative specifications including the square of the two specialization measures employed. Nevertheless, the coefficients of these variables were not statistically significant in any case.
} 


\section{Figure and Tables}

Figure 1: The spatial distribution of unemployment volatility in the EU.
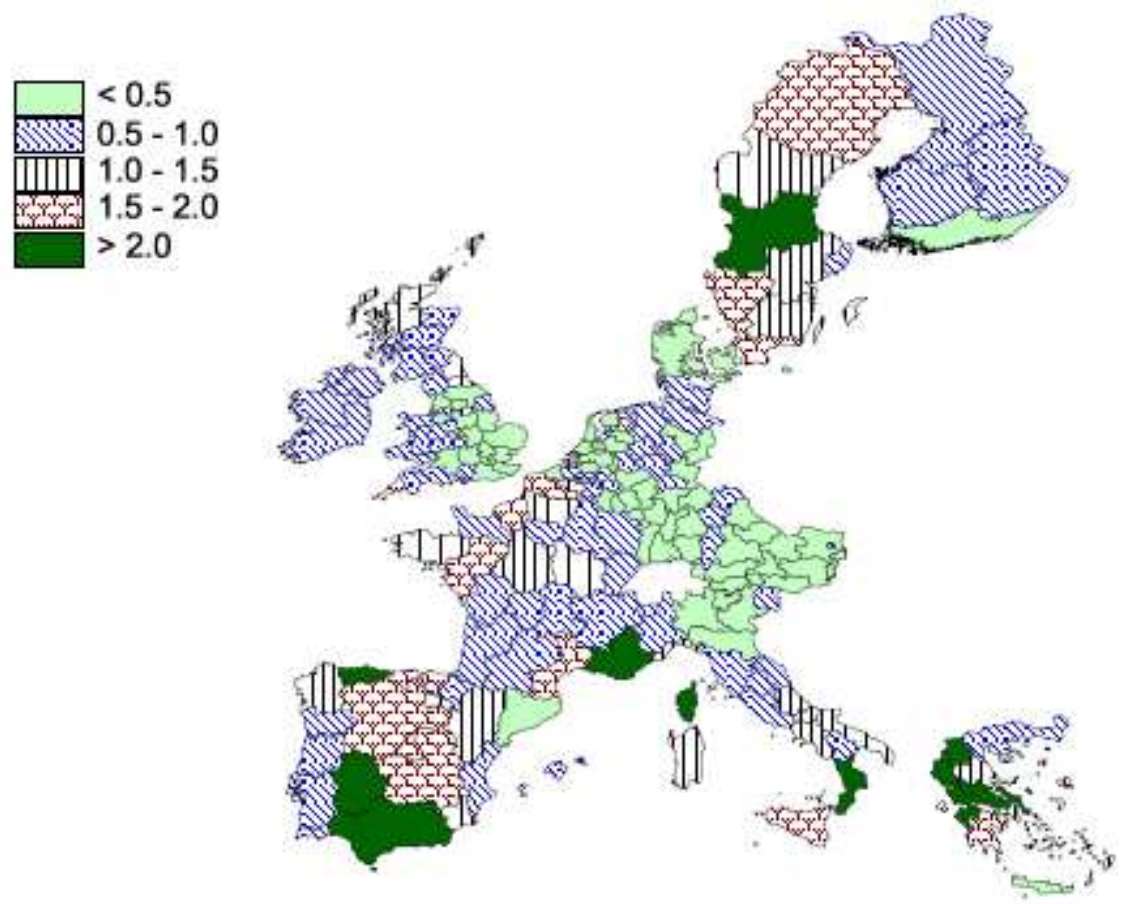

$0_{0} f$ 
Figure 2: Moran scatterplot for unemployment volatility in the EU regions.

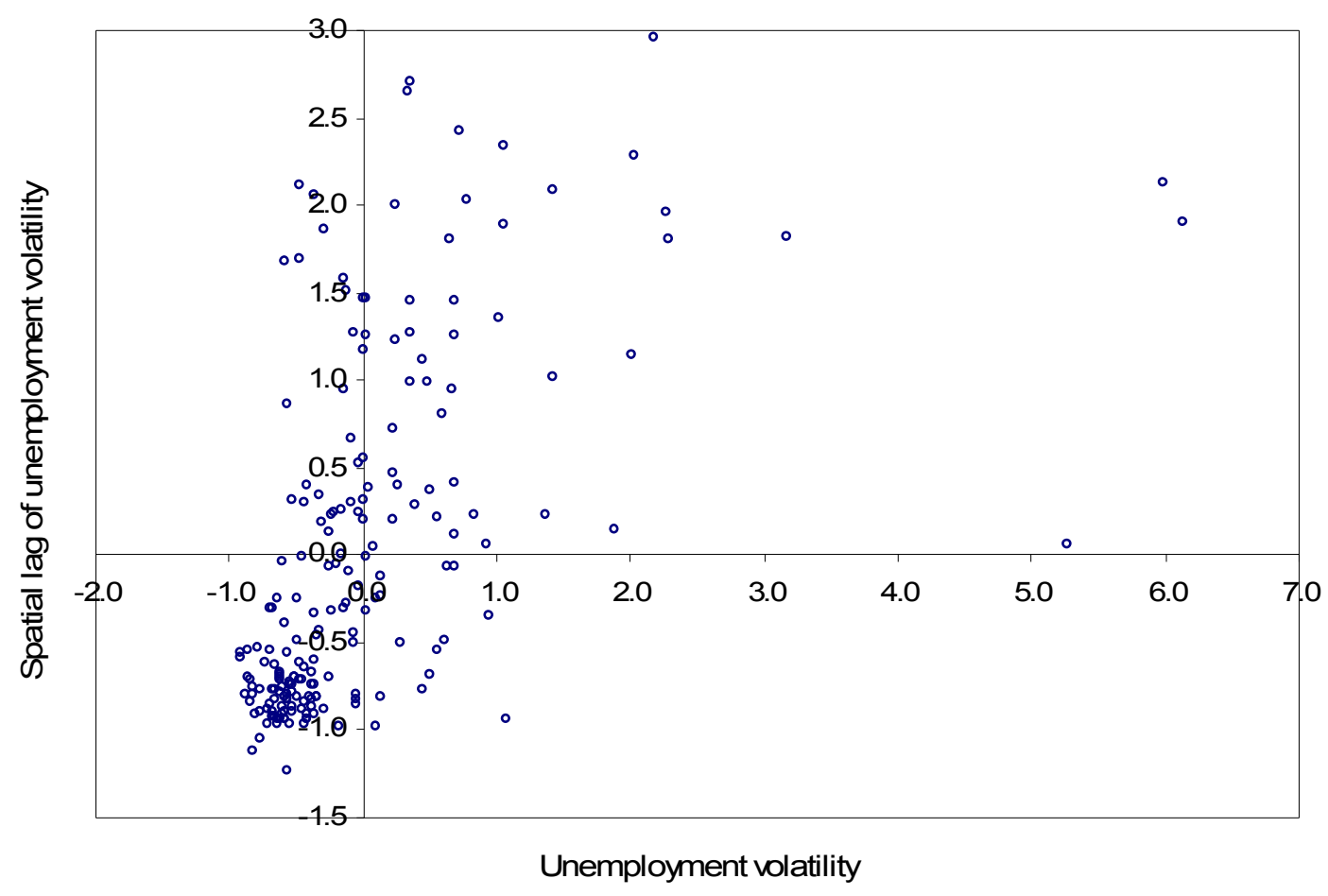


Figure 3: Scatter for unemployment volatility in the EU regions.

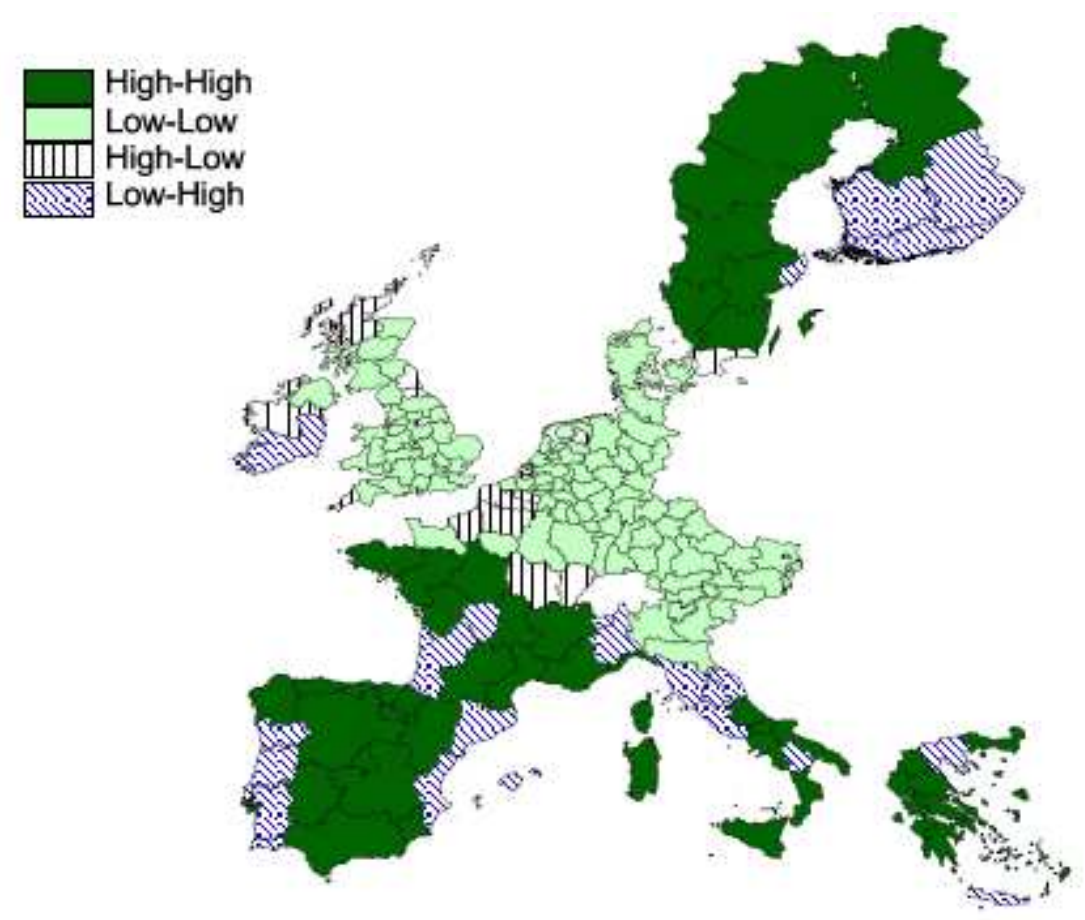


Table 1: Spatial autocorrelation tests.

\begin{tabular}{cccccc}
\hline \hline Test & Value & Mean & $\begin{array}{c}\text { Standard } \\
\text { deviation }\end{array}$ & $\begin{array}{c}\text { Standardized } \\
\text { value }\end{array}$ & p-value \\
\hline Moran's I & 0.105 & -0.005 & 0.007 & 14.745 & 0.000 \\
Geary's c & 0.794 & 1.000 & 0.040 & -5.209 & 0.000 \\
\hline \hline
\end{tabular}

Note: Inference is based on the permutation approach with 10,000 permutations (Anselin, 1995). 
Table 2: Regression analysis: unemployment volatility and absolute specialization.

\begin{tabular}{|c|c|c|c|c|c|c|}
\hline & $(2.1)$ & $(2.2)$ & $(2.3)$ & $(2.4)$ & $(2.5)$ & $(2.6)$ \\
\hline & OLS & OLS & OLS & ML-LAG & ML-LAG & ML-LAG \\
\hline$\gamma$ & $\begin{array}{c}1.298 * * * \\
(0.422)\end{array}$ & $\begin{array}{c}2.907 * * * \\
(0.449)\end{array}$ & $\begin{array}{c}3.627 * * * \\
(0.561)\end{array}$ & $\begin{array}{c}1.497 * * * \\
(0.406)\end{array}$ & $\begin{array}{c}3.011 * * * \\
(0.413)\end{array}$ & $\begin{array}{c}3.706 * * * \\
(0.513)\end{array}$ \\
\hline Herfindahl index & $\begin{array}{c}1.368 * * * \\
(0.242)\end{array}$ & $\begin{array}{c}1.069 * * * \\
(0.258)\end{array}$ & $\begin{array}{c}0.999 * * * \\
(0.255)\end{array}$ & $\begin{array}{c}1.272 * * * \\
(0.233)\end{array}$ & $\begin{array}{c}0.940 * * * \\
(0.240)\end{array}$ & $\begin{array}{c}0.873 * * * \\
(0.235)\end{array}$ \\
\hline Total employment & & $\begin{array}{l}-0.075 * \\
(0.042)\end{array}$ & $\begin{array}{l}-0.064 \\
(0.045)\end{array}$ & & $\begin{array}{c}-0.088 * * \\
(0.038)\end{array}$ & $\begin{array}{l}-0.077 * \\
(0.041)\end{array}$ \\
\hline Employment density & & $\begin{array}{c}0.049 \\
(0.039)\end{array}$ & $\begin{array}{c}0.054 \\
(0.035)\end{array}$ & & $\begin{array}{l}0.063 * \\
(0.036)\end{array}$ & $\begin{array}{c}0.068 * * \\
(0.032)\end{array}$ \\
\hline Ratio of active to total population & & $\begin{array}{c}-0.032 * * * \\
(0.006)\end{array}$ & $\begin{array}{c}-0.028 * * * \\
(0.006)\end{array}$ & & $\begin{array}{c}-0.031 * * * \\
(0.006)\end{array}$ & $\begin{array}{c}-0.026 * * * \\
(0.005)\end{array}$ \\
\hline Annual growth rate & & & $\begin{array}{l}-0.142 * \\
(0.076)\end{array}$ & & & $\begin{array}{l}-0.140^{*} \\
(0.071)\end{array}$ \\
\hline$(\text { Annual growth rate })^{2}$ & & & $\begin{array}{l}0.011 * \\
(0.007)\end{array}$ & & & $\begin{array}{l}0.011 * \\
(0.006)\end{array}$ \\
\hline Structural change & & & $\begin{array}{c}0.558 * * \\
(0.222)\end{array}$ & & & $\begin{array}{c}0.538 * * * \\
(0.203)\end{array}$ \\
\hline Spatial autoregressive parameter $(\lambda)$ & & & & $\begin{array}{c}0.828 * * * \\
(0.164)\end{array}$ & $\begin{array}{c}0.815^{* * *} * \\
(0.174)\end{array}$ & $\begin{array}{c}0.812 * * * \\
(0.177)\end{array}$ \\
\hline$\overline{\text { Log likelihood }}$ & -129.802 & -114.226 & -107.208 & -125.244 & -110.010 & -102.993 \\
\hline Akaike's information criterion & 287.604 & 262.451 & 254.4168 & 286.489 & 262.020 & 253.985 \\
\hline Moran's I & $7.095 * * *$ & $5.376 * * *$ & $4.822 * * *$ & & & \\
\hline LMERR & 2.436 & 0.521 & 0.208 & & & \\
\hline LMLAG & $11.625 * * *$ & $9.975 * * *$ & $9.844 * * *$ & & & \\
\hline R-LMERR & $8.021 * * *$ & $12.905 * * *$ & $14.502 * * *$ & & & \\
\hline R-LMLAG & $17.210 * * *$ & $22.359 * * *$ & $24.138 * * *$ & & & \\
\hline Wald test for $\lambda=0$ & & & & $25.402 * * *$ & $21.806 * * *$ & $21.001 * * *$ \\
\hline Lagrange multiplier test for $\lambda=0$ & & & & $11.625 * * *$ & $9.975 * * *$ & $9.844 * * *$ \\
\hline National dummies & Yes & Yes & Yes & Yes & Yes & Yes \\
\hline
\end{tabular}


Observations

196

196

196

196

196

196

The dependent variable is in all cases the logarithm of the standard deviation of annual unemployment rates in each region over the period 1980-2004. (2) With the only exception of the ratio of active population to total population, and the annual growth rate and its square, all the explanatory variables are expressed in logarithms. (3) *, ** and *** denotes significant at 10\%,5\% and 1\%, respectively. (4) Robust standard errors are reported in parentheses (White, 1980, 1982). 
Table 3: Regression analysis: unemployment volatility and relative specialization.

\begin{tabular}{|c|c|c|c|c|c|c|}
\hline & $(3.1)$ & $(3.2)$ & $(3.3)$ & $(3.4)$ & $(3.5)$ & $(3.6)$ \\
\hline & OLS & OLS & OLS & ML-LAG & ML-LAG & ML-LAG \\
\hline$\gamma$ & $\begin{array}{l}-0.506^{*} \\
(0.265)\end{array}$ & $\begin{array}{c}2.209 * * * \\
(0.469)\end{array}$ & $\begin{array}{c}2.781 * * * \\
(0.546)\end{array}$ & $\begin{array}{l}-0.133 \\
(0.248)\end{array}$ & $\begin{array}{c}2.452 * * * \\
(0.423)\end{array}$ & $\begin{array}{c}2.992 * * * \\
(0.492)\end{array}$ \\
\hline Herfindahl index & $\begin{array}{l}0.365 * * \\
(0.167)\end{array}$ & $\begin{array}{c}0.417 * * * \\
(0.152)\end{array}$ & $\begin{array}{l}0.317 * * \\
(0.155)\end{array}$ & $\begin{array}{l}0.360 * * \\
(0.154)\end{array}$ & $\begin{array}{c}0.398 * * * \\
(0.136)\end{array}$ & $\begin{array}{c}0.305 * * \\
(0.136)\end{array}$ \\
\hline Total employment & & $\begin{array}{c}-0.102 * * \\
(0.044)\end{array}$ & $\begin{array}{c}-0.103 * * \\
(0.047)\end{array}$ & & $\begin{array}{c}-0.107 * * * \\
(0.039)\end{array}$ & $\begin{array}{c}-0.108 * * * \\
(0.041)\end{array}$ \\
\hline Employment density & & $\begin{array}{c}0.103 * * * \\
(0.038)\end{array}$ & $\begin{array}{c}0.105 * * * \\
(0.035)\end{array}$ & & $\begin{array}{c}0.110 * * * \\
(0.034)\end{array}$ & $\begin{array}{c}0.112 * * * \\
(0.031)\end{array}$ \\
\hline Ratio of active to total population & & $\begin{array}{c}-0.041 * * * \\
(0.007)\end{array}$ & $\begin{array}{c}-0.036 * * * \\
(0.007)\end{array}$ & & $\begin{array}{c}-0.039 * * * \\
(0.006)\end{array}$ & $\begin{array}{c}-0.034 * * * \\
(0.006)\end{array}$ \\
\hline Annual growth rate & & & $\begin{array}{c}-0.159 * * \\
(0.069)\end{array}$ & & & $\begin{array}{c}-0.156 * * \\
(0.066)\end{array}$ \\
\hline$(\text { Annual growth rate })^{2}$ & & & $\begin{array}{l}0.014 * * \\
(0.006)\end{array}$ & & & $\begin{array}{c}0.014 * * \\
(0.006)\end{array}$ \\
\hline Structural change & & & $\begin{array}{l}0.460 * \\
(0.240)\end{array}$ & & & $\begin{array}{c}0.432 * * \\
(0.218)\end{array}$ \\
\hline Spatial autoregressive parameter $(\lambda)$ & & & & $\begin{array}{c}0.866^{* * * *} \\
(0.130)\end{array}$ & $\begin{array}{c}0.859 * * * \\
(0.136)\end{array}$ & $\begin{array}{c}0.858 * * * \\
(0.137)\end{array}$ \\
\hline Log likelihood & -142.240 & -118.632 & -113.300 & -136.263 & -112.802 & -107.436 \\
\hline Akaike's information criterion & 312.480 & 271.265 & 266.601 & 308.527 & 267.605 & 262.871 \\
\hline Moran's I & $9.420 * * *$ & $6.567 * * *$ & $6.099 * * *$ & & & \\
\hline LMERR & $6.859 * * *$ & 1.577 & 1.036 & & & \\
\hline LMLAG & $17.046^{* * *}$ & $15.491 * * *$ & $15.423 * * *$ & & & \\
\hline R-LMERR & $5.465 * *$ & $15.089 * * *$ & $16.831 * * *$ & & & \\
\hline R-LMLAG & $15.652 * * *$ & $29.004 * * *$ & $31.218 * * *$ & & & \\
\hline Wald test for $\lambda=0$ & & & & $44.055 * * *$ & $39.681 * * *$ & $39.174 * * *$ \\
\hline Lagrange multiplier test for $\lambda=0$ & & & & $17.046^{* * *}$ & $15.491 * * *$ & $14.423 * * *$ \\
\hline National dummies & Yes & Yes & Yes & Yes & Yes & Yes \\
\hline
\end{tabular}


Notes: (1) The dependent variable is in all cases the logarithm of the standard deviation of annual unemployment rates in each region over the period 1980-2004 (2) With the only exception of the ratio of active population to total population, and the annual growth rate and its square, all the explanatory variables are expressed in logarithms. (3) *, ** and *** denotes significant at 10\%,5\% and 1\%, respectively. (4) Robust standard errors are reported in parentheses (White, 1980, 1982). 
Table 4: The impact of the different sectors on unemployment volatility (spatial lag models).

\begin{tabular}{|c|c|c|c|c|c|c|c|c|}
\hline Sector & Coef. Est. & St. Error & Log likelih. & Moran's I & LMERR & LMLAG & R-LMERR & R-LMLAG \\
\hline Agriculture & -0.010 & 0.008 & -109.159 & $6.505 * * *$ & 1.423 & $16.345 * * *$ & $15.968 * * *$ & $30.890 * * *$ \\
\hline Mining and energy & $0.078 * * *$ & 0.026 & -106.198 & $6.363 * * *$ & 1.336 & $16.225 * * *$ & $15.273 * * *$ & $30.163 * * *$ \\
\hline Food, beverages and tobacco & $-0.085 * * *$ & 0.033 & -106.628 & $6.339 * * *$ & 1.265 & $14.992 * * *$ & $14.072 * * *$ & $27.798 * * *$ \\
\hline Textiles & $-0.028 *$ & 0.016 & -108.192 & $6.252 * * *$ & 1.202 & $15.123 * * *$ & $14.857 * * *$ & $28.777 * * *$ \\
\hline Chemical products & -0.008 & 0.025 & -109.887 & $6.006 * * *$ & 0.945 & $14.563 * * *$ & $16.738 * * *$ & $30.356 * * *$ \\
\hline Electrical and optical equipment & -0.055 & 0.039 & -108.994 & $5.446 * * *$ & 0.513 & $12.762 * * *$ & $17.103 * * *$ & $29.351 * * *$ \\
\hline Transport equipment & -0.007 & 0.028 & -109.904 & $6.223 * * *$ & 1.168 & $15.280 * * *$ & $15.919 * * *$ & $30.031 * * *$ \\
\hline Other manufacturing & $-0.038 * * *$ & 0.012 & -104.848 & $5.044 * * *$ & 0.276 & $10.242 * * *$ & $14.292 * * *$ & $24.257 * * *$ \\
\hline Construction & $0.068 *$ & 0.040 & -107.810 & $6.114 * * *$ & 1.080 & $15.733 * * *$ & $16.677 * * *$ & $31.329 * * *$ \\
\hline Distribution services & -0.027 & 0.020 & -108.810 & $5.723 * * *$ & 0.740 & $13.903 * * *$ & $16.169 * * *$ & $29.332 * * *$ \\
\hline Hotels and restaurants & -0.021 & 0.015 & -109.113 & $5.968 * * *$ & 0.931 & $14.192 * * *$ & $15.413 * * *$ & $28.674 * * *$ \\
\hline Transport, storage and communications & 0.013 & 0.015 & -109.709 & $6.151 * * *$ & 1.118 & $15.073 * * *$ & $15.592 * * *$ & $29.547 * * *$ \\
\hline Financial intermediation & 0.033 & 0.041 & -109.672 & $6.181 * * *$ & 1.110 & $15.121 * * *$ & $15.651 * * *$ & $29.662 * * *$ \\
\hline Real estate, renting and business activities & 0.008 & 0.022 & -109.856 & $7.213 * * *$ & 2.383 & $17.790 * * *$ & $19.079 * * *$ & $34.486^{* * *}$ \\
\hline Non market services & $0.042 * * *$ & 0.008 & -96.492 & $3.739 * * *$ & 0.000 & $6.120 * *$ & $12.265 * * *$ & $18.385 * * *$ \\
\hline
\end{tabular}

Non market services

Notes: (1) The dependent variable is in all cases the logarithm of the standard deviation of annual unemployment rates in each region over the period 1980-2004. (2) Spatial lag models estimated by ML. The various spatial dependence tests were calculated from the OLS residuals. (3) $*, * *$ and $* * *$ denotes significant at $10 \%, 5 \%$ and $1 \%$, respectively. (4) Robust standard errors were calculated according to White (1980, 1982). (5) All the regressions include national dummies and the following control variables: total employment, employment density, the ratio of active population to total population, the annual growth rate, the square of the annual growth rate and the amount of structural change. (6) The number of observations is 196 in all cases. 
Table A1: Descriptive statistics for the explanatory variables considered in the analysis.

\begin{tabular}{lcc}
\hline \hline Variable & Mean & St. Dev. \\
\hline Herfindahl index & 0.151 & 0.031 \\
Dissimilarity index & 0.310 & 0.144 \\
Total employment (000s) & 760.931 & 681.523 \\
Employment density & 201.094 & 640.234 \\
Ratio of active to total population (\%) & 45.774 & 7.572 \\
Average annual growth rates of per capita GDP (\%) & 2.222 & 1.129 \\
Structural change & 0.406 & 0.090 \\
Agriculture (employment share, \%) & 8.089 & 8.482 \\
Mining and energy (employment share, \%) & 1.457 & 1.179 \\
Food, beverages and tobacco (employment share, \%) & 2.684 & 1.078 \\
Textiles (employment share, \%) & 2.214 & 2.392 \\
Chemical products (employment share, \%) & 2.658 & 1.456 \\
Electrical and optical equipment (employment share, $1 \%$ ) & 2.061 & 1.252 \\
Transport equipment (employment share, \%) & 1.810 & 1.311 \\
Other manufacturing (employment share, \%) & 8.288 & 3.487 \\
Construction (employment share, \%) & 7.366 & 1.399 \\
Distribution services (employment share, \%) & 14.464 & 2.391 \\
Hotels and restaurants (employment share, \%) & 4.516 & 2.494 \\
Transport, storage and communications (employment share, \%) & 5.925 & 2.223 \\
Financial intermediation (employment share, \%) & 2.772 & 1.355 \\
Real estate, renting and business activities (employment share, \%) & 8.409 & 3.923 \\
Non-market services (employment share, \%) & 27.287 & 5.949 \\
\hline \hline
\end{tabular}

Notes: The number of observations is 196 in all cases. 
Table A2: Correlation coefficients between the explanatory variables used in the analysis.

\begin{tabular}{|c|c|c|c|c|c|c|c|}
\hline & Herfindahl index & $\begin{array}{c}\text { Dissimilarity } \\
\text { index }\end{array}$ & $\begin{array}{c}\text { Total } \\
\text { employment }\end{array}$ & $\begin{array}{c}\text { Employment } \\
\text { density }\end{array}$ & $\begin{array}{l}\text { Ratio of active to } \\
\text { total population }\end{array}$ & $\begin{array}{c}\text { Annual growth } \\
\text { rate }\end{array}$ & $\begin{array}{c}\text { Structural } \\
\text { change }\end{array}$ \\
\hline Herfindahl index & 1.000 & & & & & & \\
\hline Dissimilarity index & 0.579 & 1.000 & & & & & \\
\hline Total employment & -0.205 & -0.259 & 1.000 & & & & \\
\hline Employment density & 0.164 & 0.106 & 0.203 & 1.000 & & & \\
\hline Ratio of active to total population & -0.269 & -0.272 & 0.302 & 0.566 & 1.000 & & \\
\hline Annual growth rate & 0.009 & 0.119 & 0.043 & 0.082 & 0.160 & 1.000 & \\
\hline Structural change & 0.203 & 0.584 & -0.292 & -0.011 & -0.157 & -0.075 & 1.000 \\
\hline
\end{tabular}


Table A3: Robustness analysis: spatial error models.

\begin{tabular}{|c|c|c|c|c|c|c|}
\hline & $(\mathrm{A} 3.1)$ & (A3.2) & (A3.3) & (A3.4) & $(\mathrm{A} 3.5)$ & $(\mathrm{A} 3.6)$ \\
\hline & ML-ERR & ML-ERR & ML-ERR & ML-ERR & ML-ERR & ML-ERR \\
\hline Constant & $\begin{array}{c}1.228 * * * \\
(0.431)\end{array}$ & $\begin{array}{c}2.778 * * * \\
(0.445)\end{array}$ & $\begin{array}{c}3.519 * * * \\
(0.570)\end{array}$ & $\begin{array}{c}-0.410 \\
(0.334)\end{array}$ & $\begin{array}{c}2.055 * * * \\
(0.439)\end{array}$ & $\begin{array}{c}2.616^{* * *} \\
(0.511)\end{array}$ \\
\hline Herfindahl index & $\begin{array}{c}1.304 * * * \\
(0.243)\end{array}$ & $\begin{array}{c}1.025^{* * *} \\
(0.254)\end{array}$ & $\begin{array}{c}0.967 * * * \\
(0.255)\end{array}$ & & & \\
\hline Dissimilarity index & & & & $\begin{array}{c}0.364 * * \\
(0.155)\end{array}$ & $\begin{array}{c}0.401 * * * \\
(0.143)\end{array}$ & $\begin{array}{c}0.307 * * \\
(0.146)\end{array}$ \\
\hline Total employment & & $\begin{array}{c}-0.080 * * \\
(0.041)\end{array}$ & $\begin{array}{c}-0.068 \\
(0.043)\end{array}$ & & $\begin{array}{c}-0.104 * * \\
(0.041)\end{array}$ & $\begin{array}{c}-0.106 * * \\
(0.044)\end{array}$ \\
\hline Employment density & & $\begin{array}{c}0.056 \\
(0.038)\end{array}$ & $\begin{array}{l}0.060 * \\
(0.036)\end{array}$ & & $\begin{array}{c}0.108 * * * \\
(0.036)\end{array}$ & $\begin{array}{c}0.110 * * * \\
(0.033)\end{array}$ \\
\hline Ratio of active to total population & & $\begin{array}{c}-0.031 * * * \\
(0.006)\end{array}$ & $\begin{array}{c}-0.027 * * * \\
(0.005)\end{array}$ & & $\begin{array}{c}-0.039 * * * \\
(0.006)\end{array}$ & $\begin{array}{c}-0.034 * * * \\
(0.006)\end{array}$ \\
\hline Annual growth rate & & & $\begin{array}{c}-0.145^{* *} \\
(0.073)\end{array}$ & & & $\begin{array}{c}-0.163 * * \\
(0.067)\end{array}$ \\
\hline (Annual growth rate) $^{2}$ & & & $\begin{array}{l}0.012 * \\
(0.006)\end{array}$ & & & $\begin{array}{c}0.014 * * \\
(0.006)\end{array}$ \\
\hline Structural change & & & $\begin{array}{c}0.536 * * \\
(0.214)\end{array}$ & & & $\begin{array}{l}0.416^{*} \\
(0.225)\end{array}$ \\
\hline Spatial error parameter $(\gamma)$ & $\begin{array}{c}0.696 * * \\
(0.323)\end{array}$ & $\begin{array}{c}0.529 \\
(0.532)\end{array}$ & $\begin{array}{c}0.410 \\
(0.690)\end{array}$ & $\begin{array}{c}0.817 * * * \\
(0.192)\end{array}$ & $\begin{array}{c}0.697 * * \\
(0.344)\end{array}$ & $\begin{array}{c}0.657 * * * \\
(0.407)\end{array}$ \\
\hline Log likelihood & -128.36 & -113.752 & -106.988 & -139.1 & -117.417 & -112.394 \\
\hline Akaike's information criterion & 292.718 & 269.5031 & 261.976 & 314.12 & 276.8334 & 272.787 \\
\hline Wald test for $\gamma=0$ & $4.651 * *$ & 0.988 & 0.353 & $18.119 * * *$ & $4.116^{* *}$ & 2.611 \\
\hline Lagrange multiplier test for $\gamma=0$ & 2.436 & 0.521 & 0.208 & $6.859 * * *$ & 1.577 & 1.036 \\
\hline National dummies & Yes & Yes & Yes & Yes & Yes & Yes \\
\hline Observations & 196 & 196 & 196 & 196 & 196 & 196 \\
\hline
\end{tabular}


Notes: (1) The dependent variable is in all cases the logarithm of the standard deviation of annual unemployment rates in each region over the period 1980-2004. (2) With the only exception of the ratio of active population to total population, the annual growth rate and its square, all the explanatory variables are expressed in logarithms. (3) *, ** and $* * *$ denotes significant at $10 \%, 5 \%$ and $1 \%$, respectively. (4) Robust standard errors are reported in parentheses (White, 1980, 1982). 